\title{
Communicative Competence in a Group of Visually Impaired Children
}

\author{
Michelle Simpson, BA (Speech and Hearing Therapy) (Witwatersrand) \\ Glenda Shapiro, BA (Log) (Witwatersrand) \\ Department of Speech Pathology and Audiology, \\ University of the Witwatersrand, Johannesburg
}

\begin{abstract}
Aspects of verbal and non-verbal communicative competence of five visually-impaired six and seven year old children were investigated. The Profile of Communicative Appropriateness (Penn, 1983) was used to assess communicative competence in one discourse interaction with a known interlocutor (mother). The resultsindicated that the subjects were predominantly appropriate in terms of verbal communication, and predominantly in appropriate in terms of non-verbal communication. Severity of visual impairment influenced performance in terms of nonverbal communication. Research and therapeutic implications are discussed.
\end{abstract}

\section{OPSOMMING}

Aspekte van die verbale en nie-verbale kommunikasievermoëns van vyf visueelgestremde kinders tussen die ouderdomme ses en sewe jaar is ondersoek. Die "Profile of Communicative Appropriateness "(Penn, 1983) is gebruik om kommunikasievermoëns in een interaksiesituasie met ' $n$ bekende persoon (die moeder) te evalueer. Die proefpersone se verbale kommunikasie is as hoofsaaklik toepaslik beoordeel terwyl nieverbale kommunikasie as hoofsaaklik nie toepaslik beoordeel is nie. Die graad van gesigsgestremdheid het nie-verbaleikommunikasie beinvloed. Implikasies vir navorsing en behandeling word bespreek.

At birth, humans are the most helpless of living creatures, whereas, as adults, they are social and communicative individuals at high levels of creativity. This transformation occurs through acquisition, learning and development, which evolves as a result of continuous interaction between the environment and the individual (Affolter \& Sticker, 1980). Full sensory integrity is essential for establishing fundamental cognitive and emotional stability (Affolter \& Stricker, 1980; Wills 1965). Early sensory deficits interfere with perceptual information processing, and a child lacking a major sense such as vision understands and structures his world differently to a child with vision.

Fraiberg (1977) describes the blind child's world as one in which objects, persons and things emerge from a void as transient tactile auditory experiences, and disappear to become meaningless experiences. It is a conceptual problem for the blind infant, who must infer the identity and substantiality of an object. As language development is closely linked to stages of cognitive development, and vision plays an important role in theories of cognitive development, the significance of visual impairment in relation to language acquisition needs to be examined. Vision is the "synthesizer" of sense experience, and a visual deficit therefore imposes significant cognitive constraints on the visually-impaired baby, particularly during the sensori-motor period (Fraiberg, 1977).

McGurk (1983) reviewed some of the more recent literature on the language acquisition of visually-impaired children, and felt that visual impairment, rather than having specific determinate effects, seems to have general moderating, or modulating influences upon the development of communicative competence. Fraiberg (1977), although noting that without vision the child faces an arduous task in acquiring language, con- cludes that ultimately the blind child has equivalent language to the sighted child. Other researchers (Anderson et al. 1984; McGinnis, 1981), show that visually-impaired children's use of action words is self-directed, rather than directed to external objects, and suggest that blind children's language reflects the experience-specific conceptualisations of objects that they are able to obtain via non-visual senses. Overall, it seems that the word meaning and usage of visually-impaired children may reflect specific, experiential deficits.

Interactive experience and exchange of messages in all communicative modalities are at the basis of language development (Bullowa, 1979; Bloom, 1973), and communicative behaviours develop in early infancy arising from the matrix of adult-infant interaction (Rogow, 1982).

The sighted child literature predicts significant constraints on the visually-impaired child's learning to communicate. Bateson (1975) called the first mother-infant interchanges "protoconversations", i.e., constant or nearly constant communication in one modality (visual) and intermittent alternating communication in another, and emphasizes the importance of preverbal conversational skills in relation to later communicative development. Bullowa (1979) states that she has observed mother-infant pairs engaging in face-to-face conversations from as early as a few hours old. Overall, therefore, the path to communicative competency begins in early infancy, where babies first converse with their eyes, then their bodies (mainly hands), and finally add spoken language (Bullowa, 1979).

Rowland (1983) examined the pragmatic perspective of preverbal blind infant development and found that many schemes associated with competent language development (e.g., symbolic play) were absent. A delay in symbolic play may be 
attributed to the "self/other" confusion typical of visuallyimpaired ehitdren (Fraiberg \& Adelson, 1976). Giving and showing, which normally form the basis of the early games and turn-taking rituals that Bruner (1983) considers precursors to the joint regulation of verbal exchanges, were virtually absent. Pointing, an especially good predictor of language development (Bates et al. 1977), and reaching-as-a-request, both of which are visually-guided behaviours, were also absent. The absence of these, visually-mediated deictic behaviours from the blind child's repertoire, severely constrains the opportunities for contingent in teraction over shared referents, and to that extent the child's competence-enhancing experiences are restricted (Mulford, 1983).

Various researchers (Urwin, 1978; Anderson et al. 1984; McGinnis, 1981), have examined the nature of the interactive language patterns between a blind child and an adult speaker, and have discovered usage problems in relation to the effectiveness of the children's contributions to the conversations. These include sudden topic shifts and minimal use of communicative gesture. Controversy exists regarding blind children's use of expressive bodily action (Apple, 1972; Brieland, 1950). Many studies in the language acquisition of visuallyimpaired children may be criticised methodologically. Anderson et al. (1984) attempted to overcome some of the methodological shortcomings of previous studies, and found that at a purely structural level, the language of blind children resembles that of their sighted peers, whereas, when examined in its discourse context, there are consistent discrepancies. This, together with the fact that McGinnis (1981) feels that more research is needed on the communication of blind children, particularly in the area of gestural communication, compelled the writer to examine more specifically the communicative competence of a group of visually-impaired children. Communicative competence is:

“... the mastery of an underlying set of appropriateness rules - which are determined by culture and situation that affect the verbal and non-verbal choices in communication events."

(Wood, 1981, p. 238.)

Furthermore, since McGinnis (1981), states that the inclusion of both blind and partially-sighted subjects in a study would assist a fuller understanding of whether partial vision results in the development and use of communicative gestures, both blind and partially-sighted subjects were included in this study, which examined the communicative competence of five visually-impaired six and seven year old children in one discourse interaction each with their mothers.

\section{METHODOLOGY}

The study aimed to examine the communicative competence of five visually-impaired six to sevenyear old children, with the ultimate purpose of examining trends regarding the relationship between visual impaiment, early preverbal development, and the cumulative implications for later communcative competence.

\section{Subject selection}

Five subjects were used in a descriptive research design. All children had a visual impairment which precluded normal educational mainstreaming, and attended Prinshof School for the Partially Sighted as day scholars. The subjects were Eng- lish-speaking with a normal IQ, and a preverbal onset of visual impairment. Two subjects were bilaterally blind, and three subjects were visually-impaired.

\section{Description of the subjects}

Subjects were chosen according to the above-mentioned criteria. Rolevant biographical and clinical data are provided in table 1.

Table 1: Description of the five subjects (1-5)

\begin{tabular}{|c|c|c|c|c|c|}
\hline & Age & Sex & Aetiology & $\begin{array}{c}\text { Age of } \\
\text { onset }\end{array}$ & $\begin{array}{l}\text { Degree of } \\
\text { jimpairment }\end{array}$ \\
\hline 1 & 6 & $\mathbf{M}$ & $\begin{array}{l}\text { Hereditary } \\
\text { Absent corneas } \\
\text { bilaterally' }\end{array}$ & Congenital & $\begin{array}{l}\text { Bilateral blind- } \\
\text { ness (minimal } \\
\text { light perception) }\end{array}$ \\
\hline 2 & 6 & $\mathrm{~F}$ & $\begin{array}{l}\text { Bilateral } \\
\text { cataracts }\end{array}$ & Congenital & $\begin{array}{l}\text { Unilateral blind- } \\
\text { ness (left) } \\
\text { Adequate vision } \\
\text { in right* }\end{array}$ \\
\hline 3 & Zn & $\mathbf{M}$ & $\begin{array}{l}\text { Birthe } \\
\text { a noxia }\end{array}$ & Congenital & $\begin{array}{l}\text { Unilateral blind- } \\
\text { ness (right). } 30 \% \\
\text { vision in left: }\end{array}$ \\
\hline 4 & 6 & $\mathrm{~F}$ & Unknown & Congenital & $\begin{array}{l}\text { Bilateral blind- } \\
\text { ness - minimal } \\
\text { light perception }\end{array}$ \\
\hline 5 & 7 & $\mathbf{F}$ & $\begin{array}{l}\text { Albinism (with. } \\
\text { nystagmus) }\end{array}$ & Congenital & $\begin{array}{l}30 \% \text { vision } \\
\text { bilateraliy }\end{array}$ \\
\hline
\end{tabular}

\section{Procedure}

\section{Test environment}

Only one discourse interaction (subject 1) was conducted in the one-way observation room at the University Speech and Hearing Clinic. The other four discourse interactions were conducted in the subjects' homes using a portable video camera. According to Umiker-Sebeok (1979), conversations in more intimate surroundings, such as the child's own home, where he is more familiar and at ease, are significantly more developed.

Interaction time

A time-bed sampling of free conversational interaction (Crystal, Garmen \& Fletcher, 1976) was employed. As Penn (1983) recommends, the interaction lasted for 15 minutes.

\section{Method}

A free-play interactive situation was utilised in the testing procedure.

Prior to initiating recording, all participants were provided with the same instructions. The mothers were instructed to interact in a natural manner with their children, and the children were told that they were allowed to play freely in the room.

\section{Recording of the data}

Video and audio recordings were made of the conversational interactions, to allow for a detailed verbal and non-verbal analysis of the data obtained. According to Muma (1978), videotaping is the best recording method, as it not only allows 
a way of rechecking what was said, but it also provides a way of noting reference and communicative intent. Additionally, one of the scales of the PCA required analysis of non-verbal behaviour, and therefore, necessitated video-recording.

\section{Analysis}

\section{Materials}

The conversational sample was analysed according to the Profile of Communicative Appropriateness, (PCA; Penn, 1983). The PCA was selected as it evaluates the appropriateness of language usage along various parameters which were relevant for the study. Furthermore, the PCA includes a verbal and a non-verbal analysis, and the importance of assessing both verbal and non-verbal behaviours in visually-impaired children has been stressed (McGinnis, 1981; Apple, 1972).

\section{Transcription}

The data was transcribed using traditional English orthography. The unit of analysis employed was one-minute "chunks" of data known as the conversational unit (Penn, 1983). Ten minutes of each interaction served as the basis for analysis. Two judges, both experienced in language pathology, were employed.

\section{Conversational partner}

According to Penn (1983) the degree of familiarity with the interlocutor determines, to some extent, both the style and topic of a subject's output. Fielding and Fraser (1978) define familiarity behaviourally, in terms of the extent of previous interaction, and cognitively, in terms of the participants' knowledge of each other, and state that it is an important aspect of the speaker-listener relationship. Therefore, the writer acknowledges the limitations of the use of only one familiar conversational partner, i.e., the child's mother.

\section{Method of analysis}

The judges were given a blank PCA sheet which was compléted for each interaction, a written instruction sheet and a table exemplifying and defining each component of the profile. Judges were additionally provided with a typed transcription of the interaction (as described above). This is in accordance with Penn (1983). The judges were required to indicate the position on a five point rating scale which they felt best described the appropriateness of the communicative behaviour of each subject on the dimension under consideration during each C.U. of one minute. The five-point rating scale delineated on the PCA was employed:
Inappropriate;

Some appropriate;
Mostly inappropriate; Appropriate. Mostly appropriate and

Penn (1983) also includes a category for 'Could not Evaluate' which she requests her judges to use as little as possible. Included in the PCA analysis were the dimensions of $\mathrm{Re}$ sponse to Interlocutor; Control of Semantic Content; Cohesion; Fluency; Sociolinguistic Sensitivity and Non-Verbal Communication. The specific quantitative data obtained for each subject were tabulated on the PCA.

\section{Inter-rater reliability}

Measures of inter-rater reliability provide independent con- firmation that the data reflect a true change in subject behaviour rather than variability in observer recording (McReynolds \& Kearns, 1983). The formula advocated by them was employed to analyse inter-rater reliability.

\section{RESULTS AND DISCUSSION}

\section{Profile of communicative appropriateness}

\section{Inter-rater reliability of discourse interaction}

Inter-rater reliability was calculated by employing the formula provided by McReynolds and Kearns (1983). For the conversation involving subject 1 inter-rater reliability fell between $88 \%$ and $100 \%$ on all scales of the PCA, for subject $286 \%$ to $100 \%$, for subject $388 \%$ to $98 \%$, for subject $486 \%$ to $100 \%$, and for subject $585 \%$ to $95 \%$. According to the criteria provided by Kazdin (1977; cited by McReynolds \& Kearns, 1983), these findings may be considered as acceptable levels of inter-rater agreement. This degree of interrater reliability implies that the observations were reliable, as well as accurate (Dollagham \& Miller, 1986).

Results of the PCA

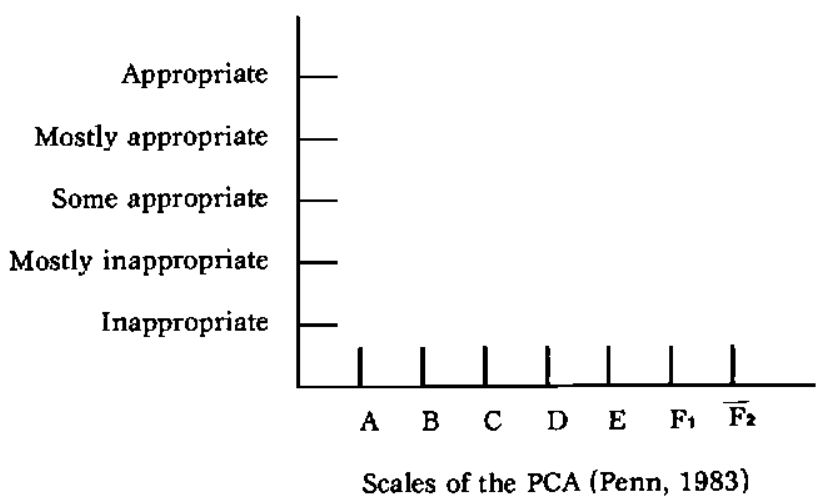

Figure 1: Performance of the five subjects on all scales of the PCA

Scales of the PCA : Key

$\mathrm{A}=$ Response to Interlocutor

$B=$ Control of Semantic Content

$\mathrm{C}=$ Cohesion

$\mathrm{D}=$ Fluency

$\mathrm{E}=$ Sociolinguistic Sensitivity

$F_{1}=$ Non-verbal Communication: Vocal Aspects

$\overline{\mathrm{F}}_{2}=$ Non-verbal Communication: Non-verbal Aspects

Subjects: Key
S1 $=0$
S2 $=\mathrm{X}$
S3 $=\Delta$
S4 $=\square$
S5 $=-$
All subjects $=$ Z

Scale A. Response to Interlocutor

As can be seen in figure 1 , all fivè subjects attained predominantly appropriate ratings for their responses to the interlocutor. Some minor inappropriate responses were observed in subject 4 , but were felt to be a function of the child's age rather than the visual impairment specifically.

Scale B. Control of Semantic Content

All of the subjects were rated as appropriate on all of the six 
behaviours reflecting Control of Semantic Content. However, two subjects (4 and 5) showed some difficulty with topic initiation and adopted passive positions in the discourse interaction. These results were felt to possibly be an artifact of the testing situation wherein the mothers used the question form of interaction, thereby reducing the opportunity for spontaneous interaction.

\section{Scale C. Grammatical Discourse Features}

All subjects were rated as predominantly appropriate in terms of grammatical cohesion.

\section{Scale D. Fluency}

All subjects were judged to be highly appropriate in terms of fluency control.

\section{Scale E. Sociolinguistic Sensitivity}

All subjects were rated as being appropriately sensitive to the demands of the communicative situations.

\section{Scale F. Non-verbal Communication}

This parameter of the PCA is divided into vocal aspects (intensity, pitch, rate, intonation and quality) and non-verbal aspects (facial expression, head movement, body posture, breathing, social distance and pantomime).

As can be seen in figure 1, all the subjects exhibited predominantly appropriate vocal aspects but were judged to be inappropriate as regards head movement, facial expression and gesture. Subjects 2, 3 and 4 made more use of gesture and facial expression but even then it was felt that more utilisation of these components of non-verbal behaviour would have improved communication.

The two subjects who were severely visually-impaired ( 1 and 4) exhibited inappropriate non-verbal behaviour, as seen in recurrent head movements, repetitive inutile hand movements, no head-turning to localise interlocutors' verbal input and reduced facial expression. The least visually impaired subjects (2 and 3) exhibited mainly reduced facial expression whilst they were able to employ the previously mentioned non-verbal behaviours. The remaining subject (5) who was moderately visually impaired, exhibited predominantly inapproriate facial expression, head movement and gesture.

As seen in table 2, the subjects' abilities to respond to the interlocutor were seen to be predominantly appropriate. This

\section{SUMMARY OF THE RESULTS}

Tahle 2: Percentage of appropriateness obtained by all subjects on all scales of the PCA

\begin{tabular}{|l|r|r|r|r|r|}
\hline \multirow{2}{*}{ PCA } & \multicolumn{5}{|c|}{ SUBJECTS } \\
\cline { 2 - 7 } & \multicolumn{1}{|c|}{1} & \multicolumn{1}{|c|}{2} & \multicolumn{1}{c|}{3} & \multicolumn{1}{c|}{4} & \multicolumn{1}{c|}{5} \\
\hline Response to Interlocutor & 90 & 90 & 100 & 80 & 100 \\
\hline Control of Semantic Content & 90 & 80 & 80 & 80 & 80 \\
\hline Cohesion & 90 & 100 & 100 & 80 & 100 \\
\hline Fluency & 100 & 100 & 100 & 100 & 100 \\
\hline Socio-linguistic Sensitivity & 90 & 100 & 100 & 100 & 100 \\
\hline Non-verbal Communication & 30 & 40 & 40 & 30 & 40 \\
\hline
\end{tabular}

is in accordance with evidence provided by Mulford (1983), who concludes that the communicat:ve coripetence of visuallyimpaired children, with a familiar interlocutor (e.g., mother), is adequate, as the familiar listener is able to assess the child's focus of attention. Some inappropriate turn-taking skills were seen, but their occurrence was minimal. A further interesting finding of this study was that the mothers of visually-impaired children tended to ask questions requiring a direct answer, or that the children carry out a request. Anderson et al. (1984) also noted this. The mothers in this study also provided fewer descriptions of the surrounding environment, rather providing labels for immediate objects or actions. Topics tended to be centred on the child, rather than the environment. Overall, it is important to note that the severe constraints predicted for visually-impaired children in terms of the early precursor development of turn-taking skills (Urwin, 1983), were not observed, i.e., the few inappropriate turn-taking skills observed did not interfere significantly with the communicative competence of the children.

In terms of Control of Semantic Content, it was seen that most subjects displayed much reliance on the interlocutor for context, particularly topic initiation. Subjects were able to maintain the flow of conversation, and to convey adequate information and vocabulary. This conflicts with the findings reported by Anderson et al. (1984), wherein they reported many instances in which the child strayed form the general conversation, and made unrelated topic shifts. Some inappropriate topic shifts were observed in subject 2 , but it was felt by both judges to be related to the child's age, rather than a function of poor semantic cohesive abilities.

All the subjects were judged to have predominantly appropriate grammatical cohesion features. Twu subjects ( 1 and 4) were noted to have instances of incorrect pronoun usage wherein they replaced "l" (when referring to themselves), with "you". Incorrect pronoun usage has been discussed extensively by various researchers (Fraiberg \& Adelson, 1976; McGinnis, 1981), who noted that blind children make significantly more personal reference errors than their sighted peers. This has been linked to poor development of body image and selfconcept (Fraiberg, 1977; Burlingham, 1965). It is interesting that the incorrect pronoun usage observed in this study occurred in the blind as opposed to the partially sighted subjects (see table 2), indicating that the more severe the visual impairment, the more likely the specific experiential deficits will have cumulative implications for later language development. Mulford (1983) found that the use of situational deictic terms by these children was worse than that of their sighted peers, indicating that blind children are unable to take the relative viewpoint of the listener. In this study, however, it was noted that the visually-impaired children were able to functionally utilise all deictic terminology correctly.

As can be seen in table 2, all subjects were judged to have appropriate fluency control, which suggests that apart from the occurrence of normal non-fluencies, the visually-impaired child does not seem to exhibit non-fluencies which interfere with the coherence or sequence of the intended message.

All subjects were judged to be predominantly appropriate in those behaviours which reflected a sensitivity to the demands of the communicative situation. As has already been mentioned, some instances of lack of sensitivity to the interlocutor were noted, and although this is in accordance with the literature (McGinnis, 1981), it is felt to be not particularly significant, having only occurred minimally. 
The most significant findings were in the area of non-verbal behaviour. This can most clearly be seen in table 2 and figure 1. In terms of the vocal aspects, all of the subjects demonstrated approriate pitch and intonation, with some instances of inappropriate intensity being reported. This was observed in both the blind and visually-impaired subjects and may be linked to the conversational reticence noted. Various non-verbal behaviours deemed to be inapproriate were observed in all of the subjects. Controversy exists regarding the presence or absence of facial expression in visually-impaired subjects (Brieland, 1950; Apple, 1972). In this study facial expression was judged to be minimal,and not consistent with the verbal message in subjects 1, 4 and 3 . This seems to be predicted in much of the literature on the preverbal development of the blind and visually-impaired child (Fraiberg, 1977; Urwin, 1983). Four of the five subjects showed inappropriate head movements. The severity was increased in the two blind subjects as opposed to the two visually-impaired subjects. This seems to indicate that the more severe the visual impairment, the worse the degree of aberrant head movement is. Inappropriate gesture (inutile hand waving), was also noted in subject 1 , although in none of the other subjects. It was felt by the raters that the gestural systems of the other four subjects, although not inappropriate, were reduced and inexpressive. This supports the findings of McGinnis(1981), who found that blind subjects used minimal expressive hand gestures to accompany their speech, relying on sometimes ambiguous verbal communication. A further finding, also described by McGinnis (1981), was that the subjects did not use head-nodding as a substitute for words. It appears, therefore, that visually-impaired children exhibit predominantly appropriate communicative competence in terms of some of the parameters, measured by the PCA (Penn, 1983). However, various inappropriate behaviours are observed in terms of non-verbal behaviours, specifically facial expression gesture and head movement.

\section{CONCLUSION}

The results of this study revealed that the visually-impaired subjects were on average, appropriate in terms of verbal communicative competence, and on average, inappropriate in terms of non-verbal communicative competence.

Non-verbal skills which appeared to be predominantly inappropriate were head movement, facial expression and gesture. The inappropriateness of the non-verbal skills tended to increase with the severity of the visual impairment, i.e., the blind subjects demonstrated aberrant head movement, whereas the partially sighted subjects showed ineffective communicative head movement. Gesture was found to be minimal, and in some cases aberrant. Instances of incorrect pronoun usage were noted in the blind subjects, and not seen in the partially sighted subjects.

The small size of the sample, and the lack of randomness in the selection of subjects, necessitates caution in generalising the results. A further limitation of the study was the use of a single familiar interlocutor, and this may have implications for future research, as Mulford (1983) states that the introduction of an unfamiliar interlocutor will provide further information pertaining to how referentially successful blind speakers are, and whether or not an "unskilled" interpreter would be able to establish the visually-impaired individual's foci of attention. However, it is felt that the significant findings in terms of nonverbal communicative skills have important implications. First$1 \mathrm{y}$, it increases the understanding of the specifically visual processes which contribute to the development of communica- tive skills (Bruner, 1983; Bates et al. 1977). Secondly, it provides practical and clinical guidelines for the development of necessary intervention procedures directed toward maximising the early communicative environment of the blind and visually-impaired child.

According to Prutting: "The communicative system is the individual's most powerful tool for getting along in this world." (1984), and it is on the basis of this that the authors believe that communication therapy with young blind, and visuallyimpaired children, will facilitate the blind child in building a model of their world (Urwin, 1983).

\section{REFERENCES}

Affolter, F. and Stricker, E. (Ed). Perceptual processes as prerequisites for complex human behaviour: a theoretical model and its application to therapy. Vienna: Hans Huber, 1980.

Anderson, Dunlea and Kekelin. Blind children's language: resolving some differences. Journal of Child Language. 11, 645-666, 1984.

Apple, M.M. Kinesic training for blind persons: a vital means of communication. New Outlook for the Blind. 66, 201-208. 1972.

Bates, E; Benigni, L; Bretherton, 1; Camaioni, L; Volterra, V. From gesture to the first word: on cognitive and social prerequisites. In Lewis, M. and Rosenblum, L (Eds.) Interattion, Conversation and the Development of Language. Canada: John Wiley and Sons Inc, 1977.

Bateson, M.C. Mother-infant exchanges: the epi-genesis of conversational interaction. In Aaronson and Rieber (Eds.) Developmental Psycholoinguistics and Communication Disorders. New York: New York Academy of Sciences, 1975.

Bloom, L. One word at a time: the use of single-word utterances before syntax. The Hague: Mouton, 1973.

Brieland, M.D. A comparative study of the speech of blind and sighted children. Speech Monographs. 17, 99-103, 1950.

Bruner, J. The acquisition of pragmatic commitments. In Golinkoff, $R$. (Ed.) The Transition from Prelinguistic to Linguistic Communication. New Jersey: Lawrence Erlbaum Associates Inc. New Jersey, 1983 .

Bullowa, M. Infants as conversational partners. In Myers (Ed.) Development of Conversation and Discourse. Edinburgh: Edinburgh University Press, 1979.

Burlingham, D. Some problems of ego development in blind children. Psychoanalytic Study of the Child. 20, 194-208, 1965.

Crystal, D; Garmen, M. and Fletcher, P. The Grammatical Analysis of Language Disability. London: Edward Amold, 1976.

Dollagham, C. and Miller, J. Observational methods in the study of communicative competence. In Schiefelbusch, R.L. (Ed.) Language Competence: Assessment and Intervention, College-Hill, 1986.

Fielding, C. and Fraser, C. Language and interpersonal relations. In, Markova, J.(Ed.): The Social Context of Language. Toronto: John Wiley and Sons, 1978.

Fraiberg, S. Insights from the Blind. Norwich: Fletcher and Son Ltd, 1977.

Fraiberg, S. and Adelson, E. Self representation in young blind children. American Foundation for the Blind. 1976.

McGinnis, A.R. Functional linguistic strategies of young blind children. Journal of Visual Impairment and Blindness. 210-214, 1981.

McGurk, H. Effectance motivation and the development of communicative competence in blind and sighted children. In Mills (Ed.) Language Acquisition in the Blind Child: Normal and Deficient. San Diego: College-Hill Press, 1983.

McReynolds and Kearns. Single-subject Experimental Designs in Communicative Disorders. Baltimore: University Park Press, 1983.

Mulford, R. Referential development in blind children. In Mills (Ed.) Language Acquisition in the Blind Child: Normal and Deficient. San Diego: College-Hill Press, 1983.

Muma, J.R. Language Handbook: Concepts, Assessment and Intervention. Prentice-Hall Inc, Englewood Cliffs, 1978.

Penn, M.A.C. Syntactic and Pragmatic aspects of aphasic language. Unpublished Doctoral Thesis, University of the Witwatersrand, Johannesburg, 1983. 
Prutting, C.A. The pragmatics of language. The South African Journal of Communication Disorders. 31, 3-5, 1984.

Rowland, C. Patterns of interaction between three blind infants and their mothers. In Mills (Ed.) Language Acquisition in the Blind Child: Normal and Deficient. San Diego: College-Hill Press, 1983.

Rogow, S. Rhythms and Rhymes: Developing communication in very young blind and multi-handicapped children. Child Care, Health and Development. 8, 249-260, 1982.

Umiker-Sebeok, D. Pre-school children's intraconversational narratives. Journal of Child Language, 1979.
Urwin, C. Early language development in blind children. Br. Psychol. Soc. Occasional Papers, 1978.

Urwin, C. Dialogue and cognitive functioning in the language deve lopment of three blind children. In Mills (Ed.) Language Acquisition in the Blind Child: Normal and Deficient. San Diego: College-Hill Press, 1983.

Wills, D. Some observations on blind nursery-school children's understanding of their world. Psychoanalytic Study of the Child. 20 , 344-364, 1965.

Wood, B.S. Children and communication. Englewood-Cliffs: PrenticeHall, 1981.

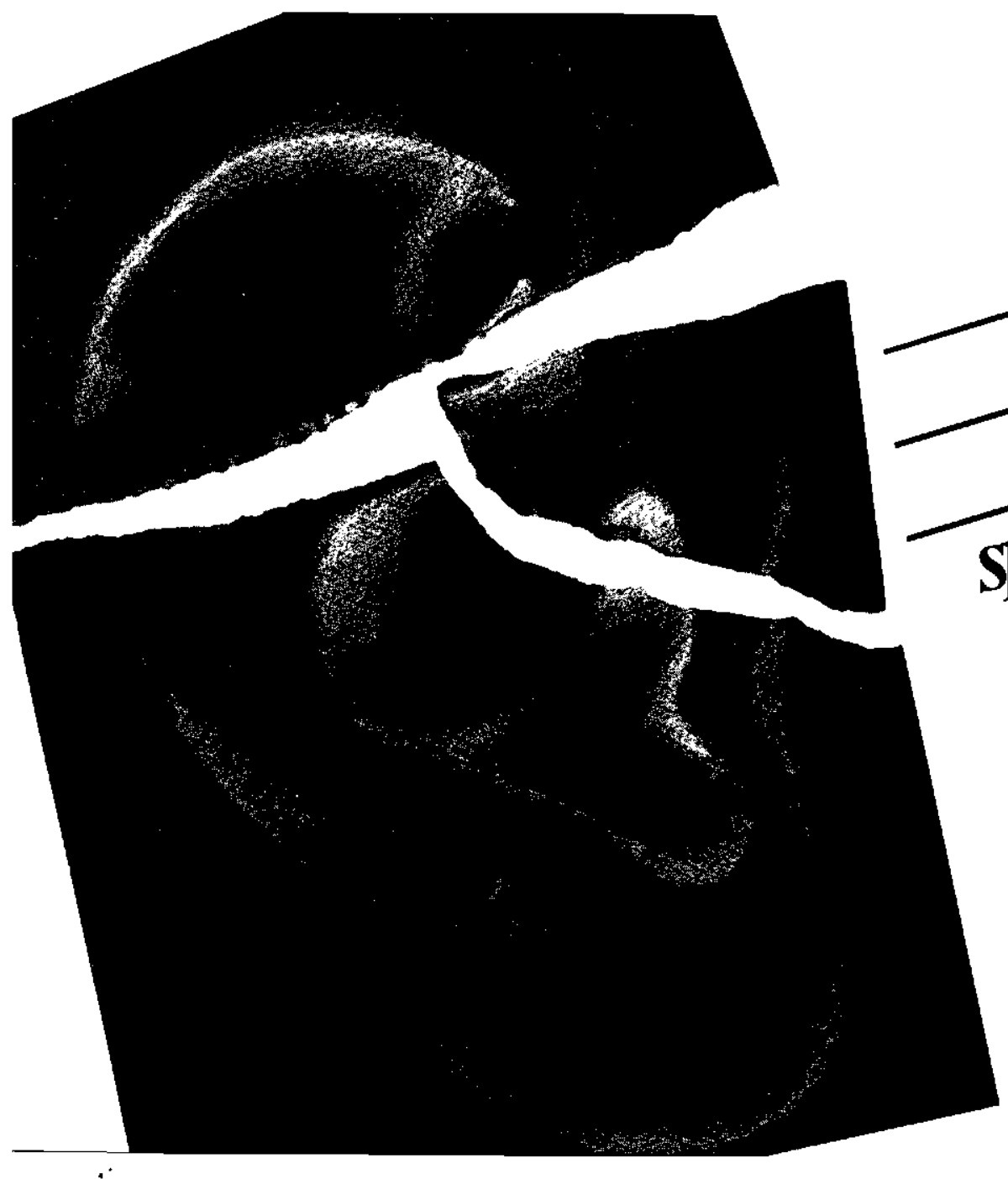
including. Austic Enclosures, meters, Acoun and imp demonsticed by prote All equipment and servicenals.

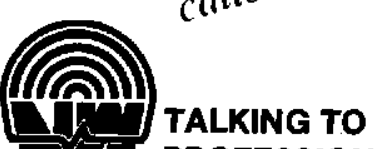

THE NEEDLER WESTOENE ORGANISATION

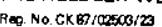

223 D.F. Malen Drive Northcliff 2196 P.O. $80 \times 2739$ Northcliff 2196

O (011) 888-1009/1087

Fex: (011) 